\title{
ENTREVISTA A FRANÇOIS ZOURABICHVILI REALIZADA EN BOGỎTÁ, EN LA ANTIGUA CASA DEL POETA PIERRE LANGUINEZ, EN AGOSTO DE $2005^{*}$
}

\author{
François Zourabichvili, Alberto Bejarano, \\ Gustavo Chirolla y César Gómez \\ doi: 10.11144/Javeriana.uph37-74.eafz
}

\begin{abstract}
Alberto Bejarano: Hablemos de tus libros y en especial del que estás planeando últimamente. Quisiéramos, además, comentar tus charlas sobre Spinoza y Deleuze ${ }^{1}$. En la introducción de tu libro Deleuze, una filosofía del acontecimiento (2004), hablas de "estilo", de "estilo deleuziano", e insistes en la necesidad de apreciar el estilo no tanto como una exterioridad, sino como una relación. Entender el "estilo" no como algo ya dado, sino como un devenir. ¿Qué piensas al respecto?
\end{abstract}

François Zourabichvili: En los años sesenta y setenta, en el marco de una gran renovación de la filosofía francesa, existe un interés particular por el lenguaje, aunque no en los mismos términos de la filosofía anglosajona, lo cual es curioso, pues las dos tradiciones se interesan al mismo tiempo por el lenguaje,

Transcripción y traducción por Alberto Bejarano, Gustavo Chirolla y César Gómez.

Para citar este artículo: Zourabichvili, F., Bejarano, A., Chirolla, G. y Gómez, C. (2020). Entrevista a François Zourabichvili realizada en Bogotá, en la antigua casa del poeta Pierre Languinez, en agosto de 2005. Universitas Philosophica, 37(74) 269-279. ISSN 0120-5323, ISSN en línea 23462426. doi: 10.11144/Javeriana.uph37-74.eafz

1 En el marco del congreso internacional "Deleuze: una imagen del pensamiento", Pontificia Universidad Javeriana, Bogotá, 25-27 de agosto de 2005. La primera de las charlas aludidas fue una conversación con profesores del Departamento de Filosofía de la Pontificia Universidad Javeriana, alrededor de su libro Spinoza : une physique de la pensée (2002), y la segunda, la conferencia "Approche du couple dedans-dehors chez Deleuze", publicada en este número de Universitas Philosophica [N.d.E.]. 
pero no de la misma manera. En Francia existe un interés que proviene sobre todo del psicoanálisis, por el hecho de no poder controlar nunca la palabra mis$\mathrm{ma}$-el inconsciente en el lenguaje-, de no poder controlar por completo el lenguaje, lo que produce un cambio en el estilo de los filósofos y, en particular, una tendencia a jugar cada vez más con las palabras. Estaba, de una parte, el psicoanálisis lacaniano, que insistía en el inconsciente y en el lenguaje, y, de otra parte, la influencia de Heidegger, el gusto por la etimología, por la descomposición de las palabras y el juego con las raíces de las palabras.

Tomemos por ejemplo el caso de Derrida, un filósofo importante, que jugó enormemente con las palabras -a veces, quizá demasiado, aunque sea, a pesar de todo, un gran filósofo-. Pero lo que vemos es una tendencia a quedarse en el juego de las palabras, a reducir el discurso filosófico al juego de palabras hasta el infinito. $Y$ es cierto que, por momentos, el discurso filosófico en los años setenta se convirtió en algo incomprensible y muy pretencioso, ya que se necesitaba inventar todo el tiempo palabras y hablar en un tercero, cuarto o quinto grado; introducir ampliamente la ironía en el discurso y ser siempre mucho más sutil que el interlocutor. En ese contexto, Deleuze siempre se mantuvo sobrio.

A. B.: En efecto, en tu libro sobre Deleuze se insiste mucho sobre el concepto de sobriedad.

F. Z.: La sobriedad es un tema principal en Deleuze. Lo utiliza en los años setenta con respecto al alcoholismo y a las drogas, [frente a las cuales] Deleuze se muestra escéptico. Es decir, de un lado, encuentra interesante las posibilidades de experimentación perceptiva con las drogas, pero al mismo tiempo insiste en la destrucción del cuerpo. Hay una bella frase en Mil mesetas (2002), donde Deleuze dice algo así como que es necesario "dejar lo suficiente en el organismo para poder continuar las formas de experimentación al día siguiente"2. En L'Abécédaire (Deleuze \& Parnet,1996b), Deleuze mostrará también su tristeza al ver a algunos de sus estudiantes devenir "autómatas" por las drogas, individuos que perdían todo deseo y toda voluntad, que se transformaban físicamente.

2 La cita que menciona F. Zourabichvili corresponde a la frase «l'organisme, il faut en garder assez pour qu'il se reforme à chaque aube » (Deleuze \& Guattari, 1980, p. 199). La traducción de la edición en español propone: "Hace falta conservar una buena parte del organismo para que cada mañana pueda volver a formarse” (Deleuze \& Guattari, 2002, p. 165) [N.d.E.]. 
Cuando Claire Parnet le pregunta a Deleuze: “ipor qué si tú estás en contra de las drogas, nunca quisiste tener un discurso moral, y nunca le dijiste a tus estudiantes qué es lo que hay o no hay que hacer?"3, Deleuze simplemente responderá que para él lo peor es que alguien sea un "autómata".

A. B.: Un "autómata" en un plano físico y mental...

F. Z.: Sí. Bueno, en cuanto a la sobriedad en el lenguaje, es algo que puede parecer un poco paradójico en Deleuze, pues en Mil mesetas hay una gran cantidad de invenciones gramaticales, palabras raras, con las que Deleuze y Guattari se entretuvieron... Aun así, el discurso de Deleuze y Guattari no jugaba con una 'hiper-ironía, ni presentaba la comprensión de una frase de tres maneras diferentes, en un tercero, cuarto o quinto grado, etc. Deleuze, por ejemplo, decía que hablaba literalmente. No le gustaba la gente que decía que una película es mala en un primer grado, pero [no] en un segundo grado... y Deleuze insistía en que si una película es mala en primer grado lo es también en el quinto grado. El discurso promedio de la filosofía se volvía ilegible e insoportable, por su pretendida sofisticación y vacuidad. El exceso de pretensión de estas derivas explica también la fuerte reacción de algunos autores en Francia que expresaban que ya no se hacía filosofía, lo que posibilitó un acercamiento con la filosofía anglosajona. En el caso de Deleuze, hay que resaltar su distancia con ese tipo de discursos. El otro tema por tratar -que ya abordé en El vocabulario de Deleuze (Zourabichvili, 2003/2007) - es la situación de algunos áulicos de Deleuze-Guattari, que, cuando escriben sobre Deleuze, en lugar de buscar una escritura propia, en lugar de llevar a cabo una experiencia personal con la filosofía de Deleuze, es decir, de pensar con Deleuze, es como si solo les bastara con utilizar las palabras de Deleuze, como si quisieran continuar su obra. Los verdaderos conceptos de Deleuze y Guattari, que tienen un contenido de pensamiento fuerte, se convierten en simples significantes. Con frecuencia, en los congresos sobre Deleuze y Guattari se escuchan 'verborragias' infinitas y terriblemente narcisistas. Deleuze era muy

3 La paráfrasis parece referirse al final de la sección "D comme Désir”, en Deleuze y Parnet, 1996b. Sin embargo, el término que utiliza repetidamente Deleuze en esta entrevista para referirse al límite negativo al que se expone el usuario de drogas es état de loque, que Monge traduce, en su versión española de El Anti Edipo, como 'andrajo' [N.d.E.]. 
discreto y no le gustaba hablar de sí mismo, pero tengo la impresión de que hay 'deleuzianos' que tienen un ego desmesurado.

A. B.: Hablando de la relación Deleuze-Guattari, tú insistes en la importancia de no marcar una diferencia [entre] un Deleuze antes de Guattari y uno después.

F. Z.: Hay algunos comentaristas que dicen: "sí, claro, Deleuze fue un gran pensador que cuando encontró al 'idiota' de Guattari se volvió loco". Hay personas que piensan que Guattari era un "idiota”. Increíble, pero se ve el caso de los que piensan que Deleuze era un gran pensador antes de Guattari, que luego llega el período de la "moda" de los setenta con Guattari y que, después, cuando Deleuze vuelve a escribir solo, regresa el Deleuze serio. Alain Badiou ha dicho eso, lo escribió, y dijo que cuando Deleuze volvió a escribir solo, en el libro sobre Foucault, aparecía un Deleuze intacto, es decir, como si hubiéramos tenido miedo de que Deleuze hubiera sido corrompido para siempre por Guattari, como si fuera solo un paréntesis ${ }^{4}$. Hay quienes piensan que Guattari fue solo un paréntesis para Deleuze. Para mí, Deleuze tenía necesidad de Guattari. Creo que, como decía Deleuze, Guattari era un gran indicador de ideas, no se dedicaba a formular conceptos de una forma ordenada, pero todo el tiempo tenía ideas y fue una fuente de inspiración formidable para Deleuze. Guattari era un personaje increíble -aunque en mi caso no lo conocí personalmente-. Para mí no hay una ruptura en la obra de Deleuze con en El Anti Edipo (1972/1985). Para mí, Deleuze, en su camino filosófico, tuvo la fortuna de encontrarse con Guattari, y luego siguió su camino, con y sin Guattari. No me gusta hablar de dos Deleuze. No me gusta diferenciar Deleuze de Deleuze-Guattari. Eso importa poco. Aun cuando se ve el caso contrario, hay algunos que dicen que, si es Deleuze solo, está bien. Pero hay otros que dicen que es Mil mesetas (1980/2002) el libro genial y que el resto de la obra de Deleuze [está compuesta por] libros muy universitarios y muy clásicos, y que el verdadero libro innovador es Mil mesetas. Hay algunos deleuzianos-guattarianos que consideran ese libro como la Biblia.

CÉSAR Gómez: A propósito de la sobriedad de Deleuze y sobre el hablar literalmente, especialmente en El Anti Edipo y en Mil mesetas, ¿esto tendría que 
ver con la idea de Deleuze y Guattari donde sostienen, a propósito de los conceptos [que utilizan], que [...] no hay que tomarlos como una metáfora?

F. Z.: Me interesa tu pregunta, porque precisamente la he trabajado mucho en El vocabulario, ya que Deleuze da la impresión de hablar siempre con metáforas. El cuerpo sin órganos no es solo el cuerpo, sino el cuerpo sin órganos de la sociedad; las máquinas de guerra no son solo los aviones de caza ni las bombas... [...] Bueno, hablando sobre la literalidad, si tomamos los ejemplos anteriores, como las máquinas de guerra, o el ritornelo, que concierne a la música -pero mucho más que eso, que se convierte en un concepto fundamental-, o, si tomamos la línea de fuga, podríamos decir que cada concepto tiene un sentido propio y que luego Deleuze les otorga un sentido figurado. A pesar de ello, Deleuze siempre dijo que no hablaba de una manera metafórica, lo cual es un poco cómico, pues Deleuze sabe perfectamente que da la impresión de hacerlo. Lo que más me impacta en Deleuze a ese respecto es que él con frecuencia insistía en un leitmotiv de su discurso oral: [con frecuencia repetía la expresión] "á la lettre", es decir, literalmente. Deleuze pedía que no se le comprendiera metafóricamente. "Yo hablo literalmente", decía. ¿Qué sentido darle a esa literalidad? En mi opinión, hablar literalmente en Deleuze es criticar la noción de "sentido propio", poner en cuestión la idea según la cual las significaciones tendrían previamente un territorio. Por ejemplo, que la arquitectura fuera la única propietaria de la noción de "línea de fuga". Deleuze siempre creyó que el contenido de sentido de las ideas va de un dominio a otro, y por ello insistía en la posibilidad de tomar de una ciencia -con lo poco que él podía comprender- lo que le era útil para sus propios problemas. Se trata de tomar un camino lógico para nuestros propios problemas. Si el ejercicio es eficaz, no se trata entonces de una metáfora, decía Deleuze. Es un poco complejo, hay que reconocerlo. Hablar literalmente es hablar por fuera de la alternativa entre sentido propio y sentido figurado. Hay filósofos que aplauden la metáfora, y hay otros que advierten en ella un peligro. En todo caso, los mejores filósofos analíticos reconocen que la metáfora no se puede evitar. Eso sí, es necesario controlar la metáfora, en especial las imágenes. Hay autores que piensan que la filosofía debería tener un discurso propio. Pero para Deleuze, la literalidad no es el "sentido propio", es, al contrario, la crítica de la oposición entre "sentido propio" y "sentido figurado". Por lo tanto, hay una crítica del concepto de metáfora, ya que la idea de metáfora supone que cierta significación pertenece 
a cierto dominio (sentido propio) y que se va a llevar esa significación a otro dominio (sentido figurado). Para Deleuze, no hay ese primer sentido y ese segundo sentido, por eso rechaza la alternativa [...], que no corresponde al nivel original de la producción de sentido. En lo que llamamos metáfora, el encuentro entre dos palabras, normalmente se aplicará un adjetivo a una palabra y se buscará el sentido propio. Pero Deleuze concibe el encuentro de dos palabras como un verdadero encuentro, es decir, donde cada palabra desterritorializa a la otra, como un devenir. Lo que hace Deleuze es reemplazar el concepto de metáfora por el de devenir. Cuando Deleuze dice: "yo no uso metáforas", no quiere decir que hable en un sentido propio y no en uno figurado: está poniendo en cuestión el concepto de metáfora, que él considera un falso concepto. La creación de sentido es algo que se produce, no es algo que preexiste. El sistema de la metáfora necesita que las significaciones estén previamente asignadas. En Deleuze lo que encontramos es el encuentro de significaciones, de palabras y de fragmentos de discursos heterogéneos que se deforman al entrar en contacto. Allí está el lugar de la producción de sentido. En la literatura, en el cine, tenemos justamente el encuentro de significaciones heterogéneas. Por ejemplo, cuando Deleuze dice en El Anti Edipo: "el inconsciente es una fábrica", normalmente se diría que es una metáfora.

A. B.: En ese sentido, la utilización de la noción de fábrica, que también fue usada por Lacan, produjo diferentes polémicas en los años setenta.

F. Z.: Bueno, lo que hay que comprender es que si "el inconsciente es una fábrica” es tomado como una metáfora, quiere decir que la significación ya está allí y [que] para intentar calificar el inconsciente se tomaría otra significación que pertenece a otro dominio, "la fábrica", lo industrial. Lo que estaríamos haciendo es utilizar este último en un sentido figurado para crear una imagen. Estaríamos superponiendo una a la otra. Pero lo que pretende Deleuze es que "el inconsciente es una fábrica" sea tomado literalmente, porque para él, el concepto de inconsciente implica las relaciones en la fábrica. Cuando Freud dice el "inconsciente es un teatro", Deleuze y Guattari dicen "el inconsciente es una fábrica”. Esto quiere decir que el significado del inconsciente freudiano implica originalmente la relación con el teatro, y Deleuze supone que es reflexionando sobre el teatro como la expresión se produce, al igual que es reflexionando sobre la fábrica como nos encontramos con el inconsciente. Para Deleuze y Guattari, el inconsciente no quiere decir nada por fuera de la relación con la noción de 
fábrica, lo mismo que en Freud el inconsciente no quiere decir nada por fuera de la relación con la noción de teatro. Podríamos tomar otro ejemplo, que Deleuze utiliza todo el tiempo: la película de Rossellini Europa 51. Allí encontramos una mujer burguesa que vive en un medio burgués, donde todo es cliché. Ella tiene previamente esquemas, percibe algo y sabe cómo actuar. Nosotros actuamos así también, vemos una silla y sabemos para qué sirve. Pero un día, en la película, en condiciones muy dramáticas, ella pierde su hijo y empieza a experimentar emociones nuevas, ayuda a obreros y, de repente, se ve trabajando en una fábrica. Un día, ella vuelve a su medio burgués y dice: "creí ver condenados". Para Deleuze, al tener ella la experiencia de la "fábrica”, comienza a perder la cadena de clichés y de lugares comunes en la que creía saber qué era una fábrica. De un momento a otro, tuvo la experiencia brutal de darse cuenta de qué era una fábrica real y qué era un obrero, y su expresión es: "vi la fábrica y creí ver condenados”. Deleuze dice que, a primera vista, es una metáfora; se trataría de una comparación con la prisión. Sin embargo, para Deleuze, la experiencia de ella no es separable de la relación con la prisión. Es como si ella tuviera una vida doble. Para Deleuze, la vida siempre es doble.

Gustavo Chirolla: Deleuze dice, cuando empieza el trabajo con Félix Guattari en El Anti Edipo y después en Mil mesetas, que el inconsciente no es un teatro, y realmente él no vuelve a hablar ni de fantasma ni de teatro para el inconsciente. Pero en Diferencia y repetición (2002) había usado, como estilo filosófico, las "dramatizaciones", y en ese momento las dramatizaciones coincidían con el teatro del inconsciente, incluso también en Lógica del sentido (1989). Después, aunque no vuelva a considerar el inconsciente como teatro, el método de la dramatización continúa en la obra de Deleuze. Creo que el lugar que tiene la dramatización en la obra posterior de Deleuze es el lugar que él mismo da a los personajes conceptuales. Ahora que tú hablabas, recordaba a un personaje conceptual que a mí me parece siempre interesante en Deleuze y que no se toca mucho: "el pájaro", "el sobrevuelo", siempre hay un sobrevuelo del pensamiento. El pensamiento vuela a una velocidad infinita. Dice Deleuze que el concepto es un sobrevuelo del pensamiento a una velocidad infinita. Yo creo que ahí hay un personaje conceptual, que encarna el acontecimiento del pensar.

F. Z.: Es una muy buena idea. [Por ejemplo], en ¿Qué es la filosofía? (1993), Deleuze utiliza ese concepto de pájaro, [lo que resulta] algo divertido porque no 
se utiliza el concepto de pájaro en filosofía. Deleuze es muy didáctico, y en un capítulo toma los conceptos de "otro", "cogito", etc. (Deleuze, 1993, pp. 21-38). En un momento dice, por ejemplo, "el pájaro [como acontecimiento]" (p. 26). Es extraño, ¿qué es en filosofía el concepto de pájaro? Pero lo que dice Deleuze es muy interesante, pues él menciona también la idea de que el filósofo debe buscar en algunas ocasiones sus inspiraciones más allá del mundo de los hombres: en las piedras, en los animales, en los vegetales [...]. En todo caso, hay una inspiración animal en el pensamiento. Estoy de acuerdo contigo, cuando te refieres a la dramatización. Hay en Deleuze efectivamente una continua inspiración teatral. En esa época se usaba mucho el concepto de simulacro, por ejemplo. Era también el momento del estructuralismo: los individuos no son solo individuos, sino que, de acuerdo con su posición en la estructura, cumplen un rol. A Deleuze siempre le interesó la puesta en escena del pensamiento, la dramatización de la filosofía.

A. B.: Actualmente tú estás reflexionando sobre las nociones de acontecimiento, advenimiento y aventura, de una manera diferente a la fenomenología. Nos decías en tu conferencia que el acontecimiento es una ruptura de sentido, es allí donde tú ubicas el concepto de aventura.

F. Z.: Quisiera oponer dos nociones de acontecimiento, ya que cada vez está más a la moda. En los años sesenta la encontramos en Deleuze y Derrida. La primera que se ocupa de una noción de acontecimiento en la filosofía contemporánea es Hanna Arendt, aunque no haya ninguna relación con Deleuze. En Derrida y Jean-Luc Nancy es diferente que en Deleuze, porque ellos estaban muy ligados al pensamiento de Heidegger. Actualmente, lo que encontramos es una "renovación" de la fenomenología, es decir, ha tomado mucha fuerza, y hay una tendencia a dividir el mundo de la filosofía entre analíticos y fenomenólogos. La fenomenología tiene una tendencia a ocuparse de la noción de acontecimiento. Ahora bien, se toma esta noción, que en su momento fue usada aparte y en contra de la fenomenología misma por la filosofía francesa, y es recuperada por los fenomenólogos, lo que en mi opinión es un poco deshonesto, porque se deja de lado la historia reciente de la filosofía. Como si "acontecimiento" fuera una noción original de los fenomenólogos. Lo que les interesa a ellos es la idea del mundo tal cual se presenta. Es la cosa en tanto que ella aparece. Eso es lo que llamo "advenimiento", como en la teología, cuando se menciona el advenimiento de Cristo. Pero para Deleuze y Foucault, el acontecimiento es otra cosa. El 
acontecimiento es una ruptura. No es el paso de la nada al ser. No es la cosa que aparece. Es la cosa que se transforma.

C. G.: Y allí es donde aparece el concepto de "aventura".

F. Z.: Sí, recordemos cuando Foucault dice: “¿por qué pienso?”, [la respuesta es] porque tengo deseos de pensar de otra manera, porque quiero deshacerme de mis propias ideas. Cuando se le dice esto a los estudiantes, es difícil hacerse comprender, porque -y no es su culpa- en los medios de comunicación hay un culto a la opinión personal y cada quien está convencido de tener algo muy importante que decir. Pero cuando Foucault dice que quiere deshacerse de sus ideas y que la filosofía no le interesa si se trata de repetir siempre las mismas ideas, estamos frente a algo distinto. Ahora, para la fenomenología el mundo aparece siempre por primera vez. Es por eso que lo que opone las dos concepciones sobre el acontecimiento, la fenomenológica y la de Deleuze y Foucault, es que en la primera el devenir es la aparición del mundo, el mundo mismo: simplemente soy yo el que lo comprendo en la verdad de su aparición; mientras que para Deleuze-Foucault el acontecimiento implica una ruptura, un cambio. Implica un momento de lo "inexplicable" puro, de irracionabilidad pura, porque precisamente hay una ruptura de sentido, se pasa a otro plano.

C. G.: En ese sentido, para Deleuze hay una especie de acontecimiento político que se expresa bajo la fórmula de Primo Levy: "la vergüenza de ser hombres"s. Este acontecimiento nos impide seguir siendo nosotros mismos.

F. Z.: Sí, incluso Deleuze utiliza con frecuencia el concepto de "vergüenza", pero ese es otro tema ${ }^{6}$. Regresando a la idea de la aventura...

A. B.: Estás intentando "deshacerte" de tus propias ideas.

F. Z.: Así lo espero, pero hay que probarlo. Es allí donde podemos ver si somos creativos o no. Aún no lo sé. Serán ustedes los que me lo digan después. Hay un concepto de aventura en algunos filósofos antiguos, aun cuando no hay una relación directa con el "acontecimiento". La aventura es algo que ocurre, pero

5 La descripción más detallada de la vergüenza que inflige en toda la humanidad la experiencia del Holocausto se encuentra en el capítulo III, "La vergüenza", de Los hundidos y los salvados, Primo Levi, 2012. [N. d. E.]

6 Sobre el uso político que hace Deleuze de la expresión de Levi, véase "R comme Résistance" en Deleuze y Parnet, 1996b. 
por fuera de la trama de la vida. La vida se va fabricando con hábitos, con coordenadas, de acuerdo con el medio al que pertenecemos. La vida sería una especie de trama que nos permite ubicarnos. La aventura no crea otra trama, es, por naturaleza, pasajera. La cuestión es saber si el acontecimiento es algo excepcional, que ocurre aparte de la trama de la vida, o si es la interrupción de la trama para constituir otra trama. Ese es mi lugar de cuestionamiento.

C. G.: Pero después de la aventura se retornaría a la trama anterior.

F. Z.: Bueno, quisiera precisar las dos vías que mencioné hace un momento: hay una gran oposición [entre], por un lado, la concepción fenomenológica que yo llamo "advenimiento" y, por otra parte, la concepción anti-fenomenológica que yo llamo "aventura”. Al interior de la aventura está la problemática que yo planteo. En mis futuros trabajos habrá artículos polémicos contrarios a la fenomenología.

\section{Referencias}

Badiou, A. (2002). Deleuze. El clamor del ser. (Trad. D. Scavino). Buenos Aires: Manantial.

Deleuze, G. (1989). Lógica del sentido. (Trad. M. Morey \& V. Molina). Barcelona: Paidós.

Deleuze, G. (1995). Conversaciones. 1972-1990. (Trad. J. L. Pardo Torío). Valencia: Pre-Textos.

Deleuze, G. (2002). Diferencia y repetición. (Trad. M. S. Delpy y Hugo). Buenos Aires: Amorrortu.

Deleuze, G., \& Guattari, F. (1980). Mille plateaux. París: Les Éditions de Minuit. Deleuze, G., \& Guattari, F. (1985). El Anti Edipo. (Trad. F. Monge). Barcelona: Paidós.

Deleuze, G., \& Guattari, F. (1988). Mil mesetas. (Trad. J. Pérez Vásquez \& U. Larraceta). Valencia: Pre-Textos.

Deleuze, G., \& Guattari, F. (1993). ¿Qué es la filosofía? (Trad. T. Kauf). Barcelona: Anagrama.

Deleuze, G. (Invitado) \& Parnet, C. (Entrevistadora) (1996a). C comme Culture. [Episodio de una serie de televisión]. En: P-A. Boutang (Productor), L'Abécédaire de Gilles Deleuze. París: Éditions Montparnasse. 
Deleuze, G. (Invitado) \& Parnet, C. (Entrevistadora) (1996b). D comme Désir. [Episodio de una serie de televisión]. En: P-A. Boutang (Productor), L'Abécédaire de Gilles Deleuze. París: Éditions Montparnasse.

Deleuze, G. (Invitado) \& Parnet, C. (Entrevistadora) (1996c). R comme Résistance. [Episodio de una serie de televisión]. En: P-A. Boutang (Productor), L'Abécédaire de Gilles Deleuze. París: Éditions Montparnasse.

Levi, P. (2012). Trilogia de Auschwitz. Si esto es un hombre. La tregua. Los hundidos y los salvados. (Trad. P. Gómez). Madrid: Editorial Océano.

Zourabichvili, F. (2002). Spinoza : une physique de la pensée. París: PUF.

Zourabichvili, F. (2004). Deleuze, una filosofía del acontecimiento. (Trad. I. Agoff). Buenos Aires: Amorrortu.

Zourabichvili, F. (2007). El vocabulario de Deleuze. (Trad. V. Goldstein). Buenos Aires: Atuel. 